CHAPTER 3

\title{
AGROBACTERIUM, A NATURAL METABOLIC ENGINEER OF PLANTS
}

\author{
P.J.J. HOOYKAAS
}

\section{Introduction}

The soil bacteria Agrobacterium tumefaciens and A. rhizogenes are the etiological agents of the plant diseases crown gall and hairy root, respectively. They belong to the family of Rhizobiaceae, and thus are related to the nitrogen fixing rhizobia. Whereas crown gall is characterized by the presence of tumors on plants, the hairy root disease is so called because of a conspicuous proliferation of roots from infection sites (Fig. 1). Plant cells in crown galls and hairy roots have two features with which they are distinguished from normal plant cells: 1) they are tumorous i.e. they proliferate in the absence of added growth factors in in vitro culture, and 2) they produce and secrete specific compounds which have been given the generic name of opines. It is now known that these novel properties of crown gall and hairy root cells are a consequence of the presence of a segment of bacterial DNA, the T(ransferred)-DNA within these cells. This bacterial DNA forms part of a large (about $200 \mathrm{kbp}$ ) bacterial plasmid which is present in virulent strains of these Agrobacteria, and is known as Ti (tumor inducing) plasmid in the case of A. tumefaciens and $\mathrm{Ri}$ (root inducing) plasmid in the case of A. rhizogenes. The T-DNA of the Ti plasmid contains a number of genes which are expressed in the transformed plant cells. Some of these are onc-genes which encode enzymes involved in the production of plant growth regulators, viz. the phytohormones indole acetic acid (an auxin) and isopentenyl-AMP (a cytokinin). Other determine enzymes which catalyze the production of the opines. The presence of these genes in the T-DNA explains the novel properties of crown gall cells. Similarly, the T-DNA of Ri plasmids contains genes called rol genes which confer the capacity to differentiate into roots on transformed cells as well as opine synthase genes. There are several different classes of opines which may be present in the T-DNA transformed plant cells (Fig. 2). This depends entirely on the types of opine synthase genes present on the T-DNA. Opine producing overgrowths form a specific ecological niche for the infecting agrobacteria, since only these can utilize the opines, which are secreted from the tumor cells, for growth. Apparently, agrobacteria are metabolic engineers which apply genetic transformation to force plant cells into producing the required metabolites. For further detailed information on Agrobacterium the reader may consult a number of recent reviews ${ }^{1-4}$. 


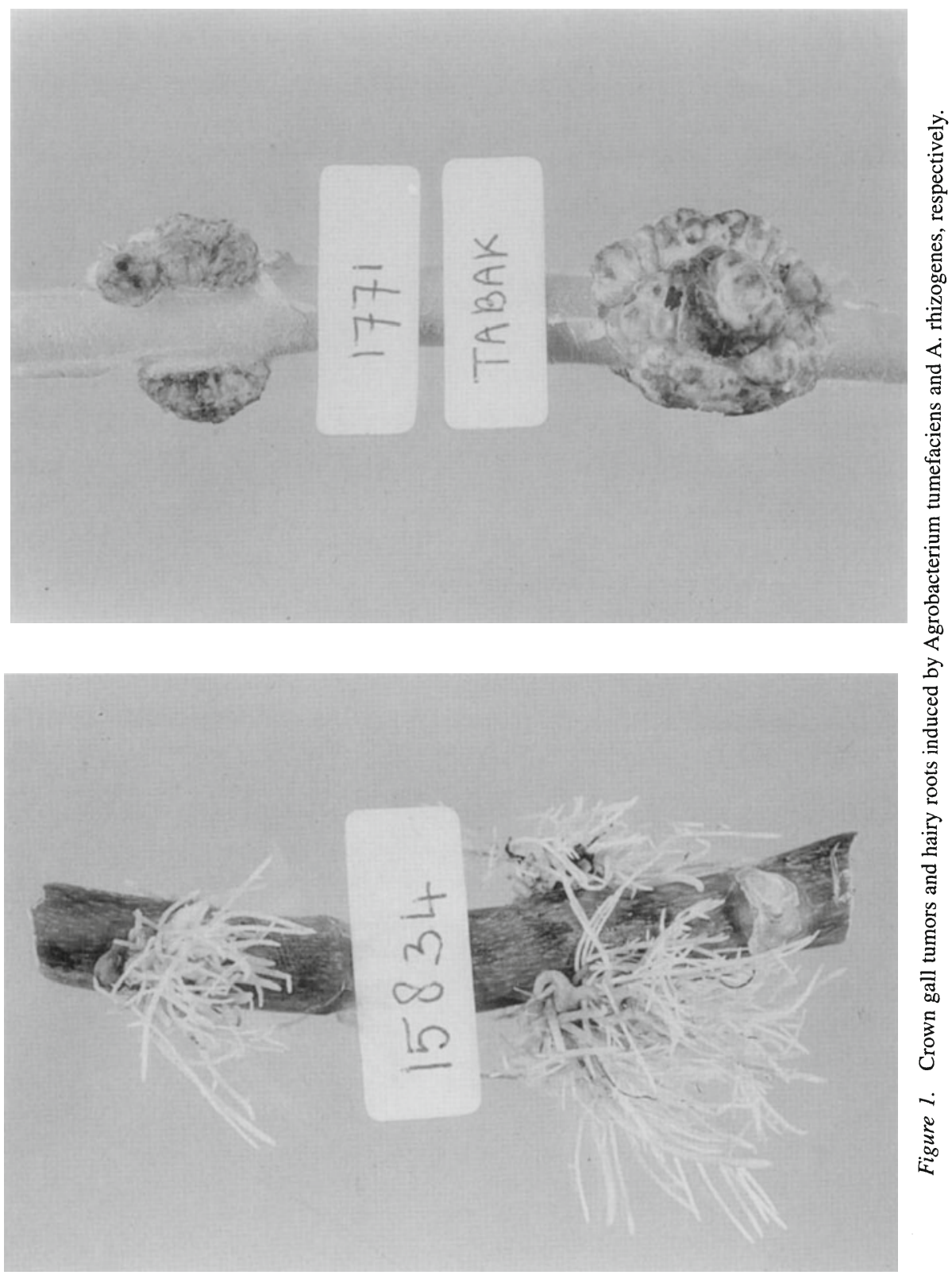


<smiles>N=C(N)NCCCCC(NC(CCC(=O)O)C(=O)O)C(=O)O</smiles>

NOPALINE<smiles>CC(C)CC(NC(CC(=O)O)C(=O)O)C(=O)O</smiles>

LEUCINOPINE<smiles>N[C@H](CC(=O)O)C(=O)CC(CC(=O)O)NC(C(=O)O)C(=O)O</smiles>

SUCCINAMOPINE<smiles>CC(NC(CCCNC(=N)N)C(=O)O)C(=O)O</smiles>

OCTOPINE<smiles>COC(O)CCNC(CCC(N)=O)C(=O)O</smiles>

MANNOPINE

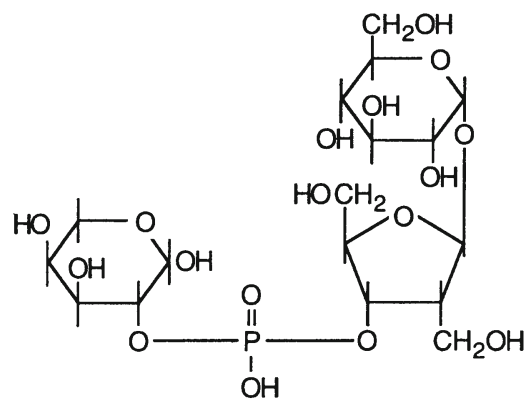

AGROCINOPINE A

Figure 2. Structural formulae of opines.

\section{Virulence genes involved in DNA transfer}

Transfer of the T-region of the Ti plasmid to plant cells is mediated by the products of virulence (vir-) genes ${ }^{2,3}$, which are located in the Virulence region adjacent to the T-region in the Ti plasmid (Fig. 3). The vir-genes are silent, until they are induced by the presence of specific phenolic compounds such as acetosyringone ${ }^{5}$ and other lignin precursors and degradation products ${ }^{6}$ (Fig. 4). These inducers become abundant in plant tissue after wounding ${ }^{5}$ which is long known to be a prerequisite for efficient tumorigenesis. Induction of the vir-genes also requires a low $\mathrm{pH}(5-6)$ and a temperature below $29^{\circ} \mathrm{C}$. The low $\mathrm{pH}$ matches of course the conditions in plant (wound) sap. Regulation of the vir-genes is mediated by the proteins of the virA and $\operatorname{vir} G$ genes, which together encode a two component regulatory system with the VirA protein acting as the chemoreceptor (of the phenolic compounds) and VirG functioning as a transcriptional activator of the vir-genes after having been forforylated by VirA on a critical aspartate residue. Regulation of the vir-genes is discussed in more detail in a review by Winans ${ }^{7}$. 


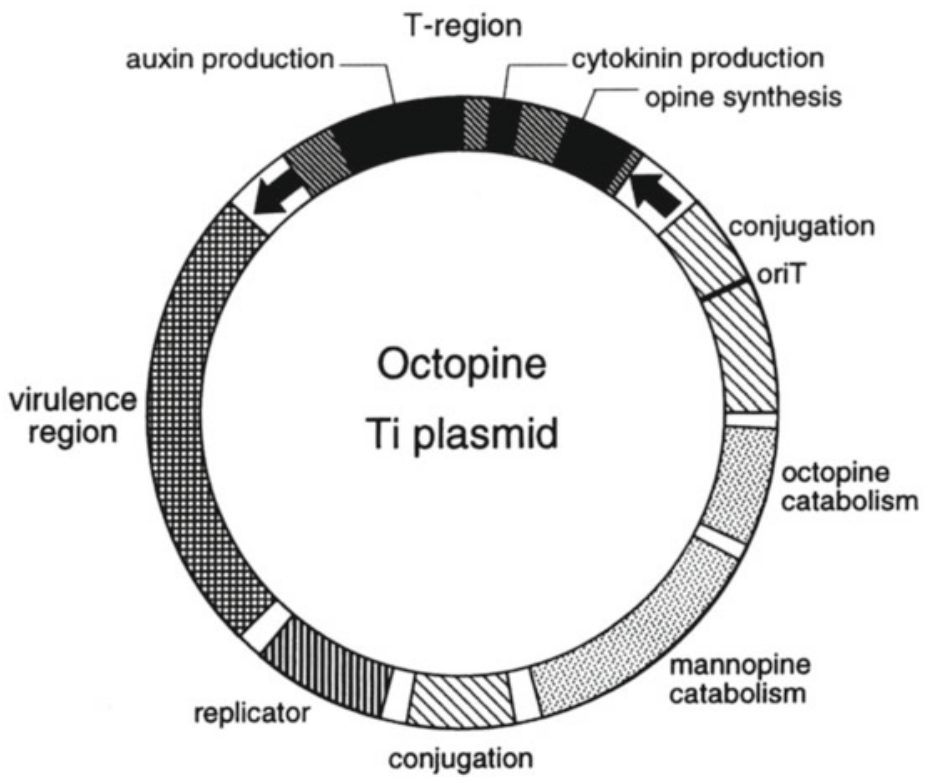

Figure 3. Genetic map of an (octopine) Ti plasmid. Arrows denote the border repeats.<smiles>[R7]c1cc(OC)c(O)c(OC)c1</smiles>

\section{$\mathrm{R}_{1}$ \\ COMPOUND INDUCTION}

$-\mathrm{C}^{2} \mathrm{CH}_{3}$

acetosyringone

$$
++++
$$

$-\mathrm{CH}=\mathrm{CH}-\mathrm{C}_{-\mathrm{OH}}=\mathrm{O}$

sinapic acid

$+++$

$-c_{-}=0$

syringaldehyde

$++$

$-\mathrm{C}^{2} \mathrm{OH}$

syringic acid

$++$

Figure 4. Inducers of the virulence genes. 
Besides virA and virG the vir-regulon consists of about 20 genes which are divided over several operons ${ }^{2,3}$. Two of these operons, the $\operatorname{vir} B$ and $\operatorname{vir} D$ operons, determine a transfer system which resembles closely the conjugative transfer systems of the wide host range incN, inc $P$ and inc $W$ plasmids ${ }^{8}$. This transfer system mediates the transfer of single stranded copies of the T-region (T-strands) to plants. In fact it is a nucleoprotein complex which is introduced into recipient plant cells. The T-strand is covalently bound to the VirD2 protein at its 5' end and can also become coated by the single stranded DNA binding protein VirE2 ${ }^{3,9}$. This latter protein protects the T-strand against nucleases during its journey to the plant cell nucleus ${ }^{10}$, while VirD2 has a nuclear localization sequence in its C-terminal part which is essential to bring the $\mathrm{T}$-strand into the plant cell nucleus ${ }^{11}$. The transfer system not only mediates transfer of the nucleoprotein T-complex to the recipient plant cells, but also of certain proteins, such as the VirF protein, which travel independently to the plant cells in order to increase the efficiency of transformation ${ }^{12}$.

Since agrobacteria induce tumors only on dicotyledonous plants, it was long thought that the host range of T-DNA transfer was restricted to this class of plants. However, later it was found that transfer is possible to monocotyledonous plants as well, but that transfer does not lead to tumorigenesis here ${ }^{13}$. More recently it was found that the virulence system of Agrobacterium can mediate DNA-transfer even to other bacteria ${ }^{14}$ and to yeast ${ }^{15}$.

\section{Plant vectors}

The natural vector system of Agrobacterium is now generally used for the genetic modification of plants. This was possible, because it was found that a) the Ti plasmid could be disarmed i.e. rendered non-oncogenic by deletion of the onc-genes without a loss of its transfer abilities, b) genes added to the T-region were co-transferred to the recipient plant cells. Now it is known that the Vir-system of Agrobacterium can mediate transfer of any genes to plant cells, provided that they are surrounded by the $24 \mathrm{bp}$ border repeats which form the ends of the natural T-region in the Ti plasmid ${ }^{16}$. These repeats are recognized by proteins encoded by the Vir-region which use these as start and end points of transfer ${ }^{8}$. Since the $\mathrm{Ti}$ and $\mathrm{Ri}$ plasmids are large (about $200 \mathrm{kbp}$ ) it is impossible to manipulate them efficiently in vitro. Two strategies have been devised to circumvent this problem. The first is to use so called intermediate vectors, into which genes of interest can be cloned in $E$. coli and which subsequently are introduced into Agrobacterium and integrate between the border repeats of a (disarmed) Ti plasmid by homologous recombination ${ }^{17}$. This cointegrate system is now only rarely used. Instead the binary vector system is applied for the genetic modification of plants almost invariably ${ }^{18}$. In this system the genes of interest are cloned directly between the border repeats which are present on a shuttle plasmid that replicates both in E. coli and Agrobacterium. After manipulation the loaded binary vector is introduced into a disarmed Agrobacterium strain, which has a Ti plasmid from which the entire T-region has been deleted, but still has an intact Vir-region (Fig. 5). This Agrobacterium host then transfers the T-region of the binary vector to the plant cells. In order to be able 
to detect plant cells transformed by Agrobacterium markers are added to the T-region which confer a selective phenotype on the transformed plant cells. Often bacterial antibiotic resistance genes serve this purpose, since plant cells - due to the presence of 'prokaryotic' chloroplasts and mitochondria - are as sensitive to certain classes of antibiotics as bacteria. The antibiotic resistance genes are modified so that they are expressed in plant cells ${ }^{19}$. Genes conferring resistance to the antibiotics kanamycin, hygromycin and gentamycin have been used in this way. Similarly, genes conferring tolerance to herbicides such as sulfonylureas and bialaphos have been employed. Transformation can be directly visualized by linking a reporter gene to the T-region. For plants the $E$. coli gene coding for $\beta$-glucuronidase (GUS) has become very popular, since the presence of this gene can be detected histochemically by adding X-Gluc (5-bromo-4-chloro-3-indolyl- $\beta$-d-glucuronide) to the plant tissue ${ }^{20}$. Presence of the gene in plant cells becomes visible by blue staining. In order to avoid potential expression (and blue staining) due to the presence of remaining agrobacteria, the gene was tailored by insertion of an intron to be expressed only by the transformed plant cells and not by the bacteria ${ }^{21}$. Recently, the gene coding for the Aequoria victoria green fluorescent protein (GFP) was modified to serve as a reporter in plant cells ${ }^{22}$. An advantage of this gene is that for the detection of its expression no substrate has to be added; the fluorescence of GFP can be seen after illumination of the transformed tissue with UVor blue light. This allows the tissue to be maintained and propagated in contrast to tissue stained for the presence of $\beta$-glucuronidase.

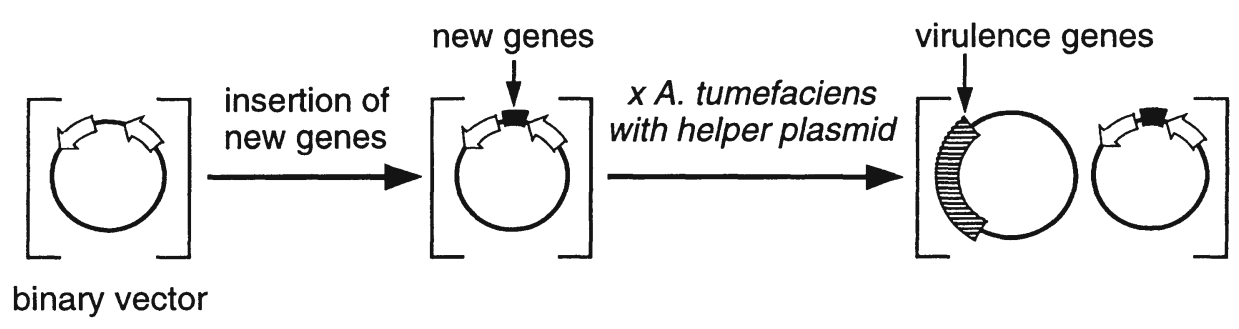

Figure 5. The binary vector system.

\section{T-DNA integration}

The T-DNA integrates into the plant genome by a process of illegitimate recombination, whereby the ends are most often well preserved ${ }^{23,24}$. Integration is accompanied by the formation of small deletions at the target locus. The process of T-DNA integration is effectuated in a similar way in different recipients including dicotyledonous and monocotyledonous plants ${ }^{25}$ and yeast ${ }^{26}$. Transgenic lines often contain only one copy of the T-DNA, but lines with multiple T-DNA copies at one or more loci in the genome are also prevalent ${ }^{27}$. Sometimes partial, truncated T-DNA copies may be present, or T-DNAs which are accompanied by segments of the original binary vector ${ }^{28}$. Integration of the T-DNA takes place at random positions in the genome, although there 
seems to be a clear preference to land into transcriptionally active regions ${ }^{29}$. In model plants such as tobacco and arabidopsis, the T-DNA has therefore been used for gene tagging ${ }^{29,30}$. Mutants obtained from T-DNA transfer experiments which have interesting phenotypes are propagated. The mutant phenotype may however not be linked to the T-DNA insertion, since plant cells receiving T-DNA seem to accumulate spontaneous mutations. However, if linkage between the mutant phenotype and the presence of the T-DNA is established in genetic experiments, the gene affected can be cloned by using the T-DNA tag as a physical marker. In this way genes involved in plant development, phytohormone signalling and brassinosteroid biosynthesis have been cloned $^{31,32}$. Tagging experiments are often done not by using ordinary binary vectors, but by employing special purpose vectors such as promoter trap, enhancer trap or activation vectors (Fig. 6). Promoter and enhancer trap vectors have a reporter gene (usually the $\beta$-glucuronidase gene) located close to one of the border repeats of the T-region ${ }^{29}$. The GUS genes in these vectors are not expressed in plant cells, unless the T-DNA inserts close to a plant promoter (promoter trap) or a plant enhancer (enhancer trap). Usually a collection of transgenic plants with these entrapment vectors is isolated which is then screened for individuals showing the desired GUS-expression pattern $^{33}$. In this way developmentally regulated, organ or cell-type specific and conditional (stress or signal compound inducible) GUS gene fusions have been obtained. The promoter/enhancer elements entrapped can then be cloned and used to drive transgenes in transgenic plants in the desired fashion.
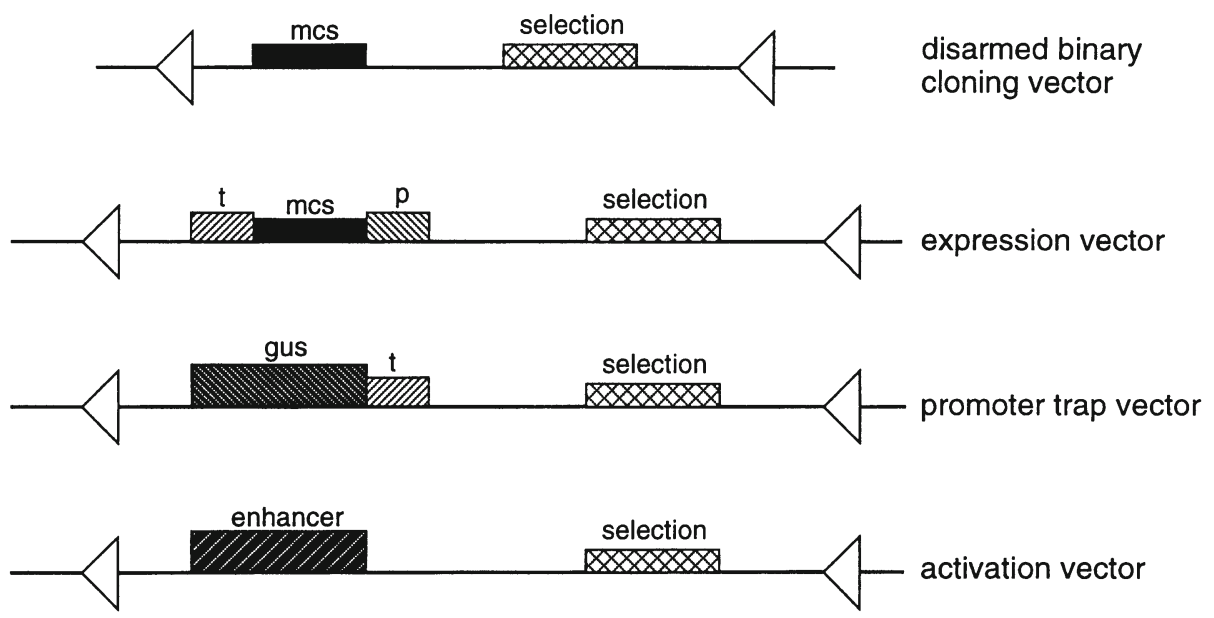

Figure 6. Plant vectors.

Activation vectors are used to make dominant mutations in plants by inducing alterations in gene expression at and around the locus of insertion ${ }^{34,35}$. These vectors have an enhancer or outward-reading promoter located close to one of the border repeats. These may induce overexpression (activation) of genes located in the vicinity of the landing site. In case an outward-reading promoter is present, it is also possible 
that transcription in the antisense direction may lead to silencing of a gene at the site of integration. Activation vectors have been used to isolate, arabidopsis calli which regenerate shoots in the absence of cytokinin ${ }^{36}$, a dehydration tolerant callus of Catherostigma plantagineum ${ }^{37}$, and an arabidopsis mutant with large lobed leaves (our unpublished results).

Recently it was found that extremely large stretches of DNA can be transferred to and stably integrated into the plant genome by the T-DNA vector system. The Binary BAC (BIBAC)-vectors used for this purpose are based on the bacterial artificial chromosome (BAC)-vectors which can contain up to $300 \mathrm{kbp}$ of cloned DNA. In the example described in literature a fragment of $150 \mathrm{kbp}$ of DNA cloned from the human genome was inserted in the tobacco genome without deletion or permuation ${ }^{38}$.

\section{Applications}

Tissues transformed by the Agrobacterium vectors described above can be regenerated into complete, fertile plants using tissue culture technology which is used for the regeneration of normal, untransformed tissue. In the fifteen years since the first transgenic (tobacco) plants were isolated many different plant species (including crops such as potato ${ }^{39}$, tomato ${ }^{40}$, cassave $^{41}$, rice $^{42}$, maize ${ }^{43}$ and wheat ${ }^{44}$ ) have been transformed with genes conferring a variety of traits. Initially these were mainly antibiotic resistance genes and reporter genes used for selection and detection of transformants. Later plants were made tolerant for various herbicides by the insertion of herbicide-insensitive target genes or of herbicide detoxifying enzymes ${ }^{45}$. Virus resistant plants were obtained by expressing the genes for viral coat proteins in them ${ }^{46}$. Crop plants were made male-sterile, an important trait in breeding, by the expression of toxic genes such as those coding for an RNAse or for the catalytic subunit of the diphtheria toxin, in the tapetum cells, where the gametophytes are generated, using a tapetum-cell specific promoter $^{47}$. By cloning a cDNA in the reverse orientation between a promoter and a terminator, a socalled antisense construct can be obtained. Introduction of these in plants leads to the silencing of the homologous endogenous genes ${ }^{48}$. This possibility has been used to inactivate many genes in plants. Thus petunia plants with altered flower colour $^{48}$, tomato producing fruits with delayed ripening ${ }^{40}$ and potato producing tubers with optimized starch content ${ }^{39}$, became available. Plants less suffering from insect damage were produced by the introduction of genes encoding Bacillus thuringiensis endotoxins ${ }^{49}$. Many more applications have gone into field trials in the meantime, and it is expected that products will find their way to the market more and more. The application of the transformation technology is limited now predominantly by the unavailability of genes which can confer the desired traits to plants. Other limiting factors concern the recalcitrance of certain plant species for transformation and variation and instability in transgene expression. Below I shall separately deal with the perspectives to solve each of these three limitations in the future. 


\section{Identifying useful genes}

One of the factors limiting the possibilities for metabolic engineering of secondary metabolism is the scarcity of cloned genes coding for enzymes participating in secondary metabolism. The focus in plant genetics is on crop species, which are important in agriculture, and on some model species such as Arabidopsis thaliana. This has made available genes involved in metabolic pathways operative in these species, some of which are present in many other plant species as well such as those for anthocyanin pigment and lignin biosynthesis. The cloned genes can now be used to find homologous genes in other species. To isolate genes for which no homologs are available requires a considerable effort. This can and has been done by purifying the enzymes first and then to use either antibodies against these or oligonucleotides synthesized on the basis of partial protein sequences to screen cDNA (expression) libraries. In this way genes involved in indole alkaloid biosynthesis in Catharanthus roseus were cloned ${ }^{50,51}$. Novel developments in map-based cloning such as the use of AFLP-markers allow to clone genes for interesting traits (which give a phenotype) now also in this way. Thus a fungal resistance gene was recently cloned from barley ${ }^{52}$. Activation tagging may be a rapid alternative to clone genes of which upregulation leads to an immediately visible phenotype (e.g. pigment formation, or tolerance of a metabolic inhibitor). In this way tagged tobacco lines were selected which could grow in the presence of an inhibitor of polyamine biosynthesis ${ }^{34}$.

\section{Recalcitrance to transformation}

A second limiting factor concerns the recalcitrance of certain plant species to transformation by Agrobacterium. This can relate to a total lack of T-DNA transfer, lack of T-DNA expression or integration, or an impossibility to regenerate the transformed cells into fertile plants. For cereals this was solved by using embryogenic callus derived from the scutellum layer of embryos as a target for transformation by Agrobacterium ${ }^{42}$. Selection of the proper target tissue for transformation was an important factor by which recalcitrance was overcome in a number of species. A number of other factors have also contributed to this. Firstly, the availability of a number of different selection markers. Some of these cannot inhibit growth in some plants or are selective, but inhibit regeneration in certain species. In such cases the availability of an alternative selection gene is essential. Secondly, the increase in knowledge about the Agrobacterium vector system itself. This taught that different Agrobacterium strains have slightly different host ranges ${ }^{12}$ and thus that it is best to compare a set of strains for effectiveness on a particular host. Also it became apparent that the Agrobacterium vir-genes need to be induced by factors present in plant wound $\operatorname{sap}^{5,6}$ and that some plants do not secrete enough of these factors for optimal induction. For that reason in many transformation protocols the addition of acetosyringone to the cocultivation medium is recommended. This same compound may also help by advancing competent cells into the S-phase of the cell cycle which is necessary for transformation ${ }^{53,54}$. Superbinary vectors on which extra copies of some of the vir-genes are present, turned out to be more effective in 
gene delivery in a number of species ${ }^{42}$. Presence of Agrobacterium also may induce tissue necrosis and cell death, for instance in Vitis vinifera ${ }^{55}$. This is due to an oxygendependent defense response of the plant cells, which can be inhibited by the addition of antioxidants to the cocultivation medium.

Development of an Agrobacterium transformation protocol for a new species may not be straightforward, but many of the tricks that were learned over the years in the many different systems will be very helpful to proceed. Alternatively, the use of Agrobacterium rhizogenes may be considered. This bacterium naturally provokes the formation of hairy roots in many plant species. Hairy roots can be propagated easily in vitro ${ }^{56}$, but often can be regenerated into complete plants. Such plants usually have phenotypes by which they are distinguished from normal plants. The most conspicuous differences are that they are shorter, bushier and have leaves which are wrinkled ${ }^{57}$. The T-DNA of the Ri plasmid can be used for the delivery of novel genes into plants, after these have been inserted in the $\mathrm{T}$-region by an intermediate vector (cointegrate system). Agrobacterium rhizogenes can also deliver the T-region from a binary vector (with border repeats from a Ti plasmid) efficiently into plants ${ }^{58}$. Co-transformation of the Ri plasmid T-DNA and the binary vector T-DNA is high, so that it suffices to screen amongst hairy roots for the presence of this latter T-DNA. If the two T-DNAs integrate at different positions in the genome (often but not always the case) they can be separated from each other in the offspring. Amongst the offspring thus seedlings are present which lack the Ri T-DNA and have a normal phenotype, but still have the binary vector T-DNA. When it is not necessary to obtain complete transgenic plants, the use of transgenic cell or tissue cultures can be considered. By transformation with Ri T-DNA fast growing hairy root cultures can be obtained, which may produce secondary metabolites as efficiently as normal roots; in case the interesting metabolites are produced in the shoot, shoot cultures may be useful, which can be produced by transformation with a "shooty" Agrobacterium strain ${ }^{59}$, in the possession of an active ipt gene.

\section{T-DNA expression}

The genes in the natural T-DNAs of Agrobacterium are expressed in plant cells due to the presence of regulatory signals (promoters, terminators) surrounding the coding regions of these genes which are recognized by the transcription machinery of the plant. These same regulatory signals have been used extensively also to drive other genes for expression in plants, besides other derived from plant genes or from plant virusses such as the $35 \mathrm{~S}$ promoter of cauliflower mosaic virus. For a detailed discussion see the chapter by Memelink. A problem which is often encountered in transgenic plants relates to variation and instability of the expression of the introduced transgenes, and aberrant segregation of the transgene in the offspring. The T-DNA itself is stable and behaves as a normal plant gene in the sense that mutation of it is extremely rare (frequency less than $\left.10^{-4}\right)^{60}$. Instability of T-DNAs may be more apparent if there are (direct) repeats present within the T-DNA due to intrachromosomal recombination ${ }^{61}$. Besides due to problems with expression (see below) aberrant segregation ratios may sometimes be caused by the fact that the transgenic plant under study is a periclinal chimera, consisting of both transgenic 
cells and normal cells ${ }^{62}$. Also the occurrence of polyploidy or aneuploidy during transformation may lead to aberrant segregation of the transgene. It is therefore advisable to check the genome composition of the transgenic plants and select those which have remained normal diploids. However, the most important causes of variation and instability of the expression of transgenes in different transgenic plants are differences in copy number or organization of the transgenes and position effects, the influence of the surrounding chromosomal DNA on the transgenes. It can be imagined that after insertion within a transcriptional unit of the plant chromosome transcription of the transgenes may be inhibited (due to generation of antisense transcripts from the neighbouring plant promoter and collision of the two transcriptional apparatuses transcribing the chromosomal plant gene and the transgene near the border repeat, respectively) or stimulated due to the presence of plant enhancers or plant promoters effective in the same direction as the transgene ${ }^{63}$. Besides the neighbouring chromosomal DNA may have sequences that direct DNAmethylation and thus silencing of the area ${ }^{64}$. Evidence suggests that the chromosomes are attached at many sites to a protein core, the matrix or scaffold, by specific sequences, the matrix or scaffold attachment sequences (MARs or SARs) ${ }^{65}$. The chromosomal DNA located between two MARs is insulated against influences from sequences located in other neighbouring loops. Surrounding transgenes by cloned MAR sequences may prevent position effects to a large extent, probably by insulating the transgenes against the influence of neighbouring genes of the host plant ${ }^{65,66}$.

Most observations suggest that there is no linear relationship between the copy number of the transgene and the level of expression. This is not only due to the important influence of neighbouring sequences on expression as described above, but also due to interactions between the transgenes themselves which may lead to silencing. This penomenon is related to co-suppression, the silencing of an endogenous plant gene due to the introduction of a homologous transgene ${ }^{67,68}$. The molecular mechanism underlying co-suppression is not known, but it is being used to inactivate plant genes just like antisense suppression. Co-suppression and antisense expression can lead to the inactivation of transgenes, but inactivation is often not complete ${ }^{67}$. This can be seen for instance in petunia, where such constructs were introduced to inhibit pigment formation ${ }^{48}$. However, not only plants with white flowers were obtained, but also plants with variegated flowers which still had a faint coloration overall or which were still coloured in certain parts of the flowers. The frequent occurrence of co-suppression phenomena in plants has made transgenic lines with simple, single copy inserts the preferred choice in research and application. This is a major reason that Agrobacterium transformation by which such single copy lines can be readily obtained is now replacing methods of direct gene transfer (electroporation, particle gun) which almost invariably give complex integration patterns of transgenes.

\section{Novel tools}

To increase the flux through a pathway for secondary metabolite production it may be desirable to block a competitive pathway. As described above this may be accomplished by the use of antisense or sense (co-suppression) constructs. However, this usually does 
not lead to complete inactivation. A gene disruption would however lead to a complete loss of gene activity. Transposons form a useful tool to accomplish this ${ }^{69}$. If these are not present naturally in the host plant of interest, they can be introduced from a heterologous source. The Ac-Ds and En-I transposon systems from maize have been introduced into several other plant species to induce transposon-tagged mutations ${ }^{69,70}$. Mutants can be identified by phenotype. Reversely, one can screen in libraries of transposon-tagged mutants, which are available for arabidopsis and petunia, for insertions in the gene of interest by PCR, and thus identify individuals in which there is a mutation in this gene ${ }^{71}$. A similar strategy has been used to identify mutants with a T-DNA insertion in the gene of interest in a large collection of T-DNA insertion mutants of Arabidopsis thaliana ${ }^{72,73}$. However, it will be feasible only for few plant species to assemble such a large collection of insertion mutants. Gene targeting might become an alternative especially for plants for which such collections are not readily available. Gene targeting is the directed integration of transgenes at a preferred position in the genome by homologous recombination. This has been used to disrupt or modify genes not only in prokaryotes and unicellular eukaryotes such as yeast, but also in mammals such as the mouse. Knock-out mice in which a specific gene is disrupted by an introduced transgene now play an important role in medical research. Unfortunately, using similar technology as in mouse did not lead to an efficient system for routine gene targeting in plants yet ${ }^{74}$, but there is optimism that for instance the introduction of enzymes from other organisms ${ }^{75}$ may help to overcome this barrier soon. The recent finding of efficient gene targeting in the moss Physcomitrella patens suggests that there may be significant interspecies differences for targeting, or that targeting may be achieved much more readily in haploid or gametophytic cells ${ }^{76}$.

Transgenic plants often contain T-DNA constructs in which not only the transgene of interest is present, but also certain selection markers for instance. This may be an undesired situation, since it prevents the use of the same selection marker in renewed transformation of the already transgenic line or to perform crosses with other transgenic lines carrying the same selection gene. Also for public acceptance in the market it may be beter if these selection genes are absent from transgenic crops. Recently, a method was developed by which such markers can be deleted from the genome ${ }^{77}$. The method uses site specific recombination systems from bacteria (Cre, lox system) or yeasts (FLP, frt system). The genes to be deleted from the plant genome are surrounded by the recognition sequences (30-50 bp sequences) of such a site specific recombinase. If these sequences are in a direct repeat orientation the sequences in between can be deleted by the recombinase expressed from a plant promoter. The recombinase gene can be introduced or expressed transiently in the transgenic plant from which the selection genes have to be deleted, or can be introduced by crossing with a plant in which this gene is stably present already. Another possibility to obtain marker-free plants was recently suggested. Here the ipt gene, which is naturally present in the T-DNA and which determines cytokinin production, is present within the Ac transposon located in the binary vector T-DNA ${ }^{78}$. Presence of ipt induces shoot formation. Selection now can be on shoots which are formed in the absence of cytokinin in the culture medium. These abnormal (due to the presence of the ipt gene) shoot lines regenerate normal shoots spontaneously, which lack the ipt gene due to the loss of the Ac element. 
Although much has been achieved during the last fifteen years in the refinement of the Agrobacterium system as a tool for plant transformation it will be clear that further modifications and assets are needed to comply with specific demands. It is in my mind without doubt that future developments will turn this vector system even more sophisticated and versatile than it is already today.

\section{References}

1 Binns, A.N. and Thomashow, M.F. (1988). Cell biology of Agrobacterium infection and transformation of plants. Ann. Rev. Microbiol. 42, 575-606.

2 Hooykaas, P.J.J. and Beijersbergen, A.G.M. (1994). The virulence system of Agrobacterium tumefaciens. Ann. Rev. Phytopathol. 32, 157-179.

3 Sheng, J. and Citovsky, V. (1996). Agrobacterium-plant cell DNA transport: have virulence proteins, will travel. Plant Cell 8, 1699-1710.

4 Dessaux, Y., Petit, A. and Tempé, J. (1993). Chemistry and biochemistry of opines, chemical mediators of parasitism. Phytochemistry 34, 31-38.

5 Stachel, S.E., Messens, E., Van Montagu, M., et al. (1985). Identification of the signal molecules produced by wounded plant cells that activate T-DNA transfer in Agrobacterium tumefaciens. Nature 318, 624-629.

6 Melchers, L.S., Regensburg-Tuïnk, A.J.G., Schilperoort, R.A. and Hooykaas, P.J.J. (1989). Specificity of signal molecules on the activation of Agrobacterium virulence gene expression. Mol. Microbiol. 3, 969-977.

7 Winans, S.C. (1992). Two-way chemical signaling in Agrobacterium -plant interactions. Microbiol. Rev. 56, 12-31.

8 Lessl, M. and Lanka, E. (1994). Common mechanisms in bacterial conjugation and Ti-mediated T-DNA transfer to plant cells. Cell 77, 321-324.

9 Zupan, J. and Zambryski, P. (1997). The Agrobacterium DNA transfer complex. Crit. Rev. Plant Sci. 16, 279-295.

10 Rossi, L., Hohn, B. and Tinland, B. (1996). Integration of complete transferred DNA units is dependent on the activity of virulence E2 protein of Agrobacterium tumefaciens. Proc. Natl. Acad. Sci USA 93, 126-130.

11 Ballas, N. and Citovsky, V. (1997). Nuclear localization signal binding protein from Arabidopsis mediates nuclear import of Agrobacterium VirD2 protein. Proc. Natl. Acad. Sci. USA 94, 10723-10728.

12 Regensburg-Tuïnk, A.J.G. and Hooykaas, P.J.J. (1993). Transgenic N.glauca plants expressing bacterial virulence gene virF are converted into hosts for nopaline strains of A.tumefaciens. Nature 363, 69-71.

13 Hooykaas-Van Slogteren, G.M., Hooykaas, P.J.J. and Schilperoort, R.A. (1984). Expression of $\mathrm{Ti}$ plasmid genes in monocotyledonous plants infected with Agrobacterium tumefaciens. Nature 311, 763-764.

14 Beijersbergen, A., Den Dulk-Ras, A., Schilperoort, R.A., et al. (1992). Conjugative transfer by the virulence system of Agrobacterium tumefaciens. Science 256, 1324-1327.

15 Bundock P., Den Dulk-Ras, A., Beijersbergen, A., et al. (1995). Trans-kingdom T-DNA transfer from Agrobacterium tumefaciens to Saccharomyces cerevisiae. EMBO J. 14, 3206-3214.

16 Yadav, N.S., Vanderleyden, J., Bennett, D.R., et al. Short direct repeats flank the T-DNA on a nopaline Ti plasmid. Proc. Natl. Acad. Sci. USA 79, 6322-6326. 
17 Zambryski, P., Joos, H., Genetello, C., et al. (1983). Ti plasmid vector for the introduction of DNA into plant cells without alteration of their normal regeneration capacity. EMBO J. 2, 2143-2150.

18 Hoekema, A., Hirsch, P.R., Hooykaas, P.J.J., et al. (1983). A binary plant vector strategy based on separation of vir and T- region of the Agrobacterium tumefaciens Ti-plasmid. Nature 303, 179-180.

19 Bevan, M. (1984). Binary Agrobacterium vectors for plant transformation. Nucleic Acids Res. 12, 8711-8721.

20 Jefferson, R.A., Kavanagh, T.A. and Bevan, M.W. (1987). GUS fusions: $\beta$-glucuronidase as a sensitive and versatile gene fusion marker in higher plants. EMBO J. 6, 3901-3907.

21 Vancanneyt, G., Schmidt, R., O'Connor-Sanchez, A., et al. (1990). Construction of an intron-containing marker gene: splicing of the intron in transgenic plants and its use in monitoring early events in Agrobacterium -mediated plant transformation. Mol. Gen. Genet. 220, 245-250.

22 Haseloff, J., Siemering, K.R., Prasher, D.C. and Hodge, S. (1997). Removal of a cryptic intron and subcellular localization of green fluorescent protein are required to mark transgenic Arabidopsis plants brightly. Proc. Natl. Acad. Sci. USA 94, 2122-2127.

23 Tinland, B. (1996). The integration of T-DNA into plant genomes. Trends Plant Science 1, 178-184.

24 Mayerhofer, R., Koncz-Kalman, Z., Nawrath, C., et al. (1991). T-DNA integration: a mode of illegitimate recombination in plants. EMBO J. 10, 697-704.

25 Hiei, Y., Ohta, S., Komari, T., et al. (1994). Efficient transformation of rice (Oryza sativa L.) mediated by Agrobacterium and sequence analysis of the boundaries of the T- DNA. Plant J. 6, 271-282.

26 Bundock, P. and Hooykaas, P.J.J. (1996). Integration of Agrobacterium tumefaciens T-DNA in the Saccharomyces cerevisiae genome by illegitimate recombination. Proc. Natl. Acad. Sci. USA 93, 15272-15275.

27 Deroles, S.C. and Gardner, R.C. (1988). Analysis of the T-DNA structure in a large number of transgenic petunias generated by Agrobacterium -mediated transformation. Plant Mol. Biol. 11, 365-377.

28 Van der Graaff, E., Den Dulk-Ras, A. and Hooykaas, P.J.J. (1996). Deviating T-DNA transfer from Agrobacterium tumefaciens to plants. Plant Mol. Biol. 31, 677-681.

29 Koncz, C., Németh, K., Rédei, G.P., et al. (1992). T-DNA international mutagenesis in Arabidopsis. Plant Mol. Biol. 20, 963-976.

30 Forsthoefel, N.R., Wu, Y., Schulz, B., et al. (1992). T-DNA insertion mutagenesis in Arabidopsis: prospects and perspectives. Aust. J. Plant Physiol 19, 353-366.

31 Azpiroz-Leehan, R. and Feldmann, K.A. (1997). T-DNA insertion mutagenesis in Arabidopsis: going back and forth. TIG 13, 152-156.

32 Szekeres, M., Németh, K., Kauschmann, A., et al. (1998). Brassinosteroids rescue the deficiency of CYP90, a cytochrome P450, controlling cell elongation and de-etiolation in Arabidopsis. Cell $85,171-182$.

33 Lindsey, K., Wei, W., Clarke, M.C., et al.. (1993). Tagging genomic sequences that direct transgene expression by activation of a promoter trap in plants. Transgenic Res. 2, 33-47.

34 Walden, R., Fritze, K., Hayashi, H., et al. (1994). Activation tagging: a means of isolating genes implicated as playing a role in plant growth and development. Plant Mol. Biol. 26, 1521-1528.

35 Van der Graaff, E. and Hoogkaas, P.J.J. (1996) Improvements in the transformation of Arabidopsis thaliana $\mathrm{C}_{24}$ leaf-discs by Agrobacterium tumefaciens. Plant Cell Rep. 15, 572-577.

36 Kakimoto, T. (1996). CKI1, a histidine kinase homolog implicated in cytokinin signal transduction. Science 274, 982-985.

37 Furini, A., Koncz, C., Salamini, F., et al. (1997). High level transcription of a member of a repeated gene family confers dehydration tolerance to callus tissue of Craterostigma plantagineum. EMBO 


\section{J. 16, 3599-3608.}

38 Hamilton, C.M., Frary, A., Lewis, C., et al. (1996). Stable transfer of intact high molecular weight DNA into plant chromosomes. Proc. Natl. Acad. Sci USA 93, 9975-9979.

39 Visser, R.G.F., Somhorst, I., Kuipers, G.J., et al. (1991). Inhibition of the expression of the gene for granule-bound starch synthase in potato by antisense constructs. Mol. Gen. Genet. 225, 289-296.

40 Smith, C.J.S., Watson, C.F., Ray, J., et al. (1988). Antisense RNA inhibition of polygalacturonase gene expression in transgenic tomatoes. Nature 334, 724-726.

41 Li, H.-Q., Sautter, C., Potrykus, I., et al. (1996). Genetic transformation of cassave (Manihot esculenta Crantz). Nature Biotechnology 14, 736-740.

42 Hiei, Y., Komari, T. and Kubo, T. (1997). Transformation of rice mediated by Agrobacterium tumefaciens. Plant Mol. Biol. 35, 205-218.

43 Ishida, Y., Saito, H., Ohta, S., et al. (1996). High efficiency transformation of maize (Zea mays L.) mediated by Agrobacterium tumefaciens. Nature Biotechnology 14, 745-750.

44 Cheng, M., Fry, J.E., Pang, S., Zhou, H., Hironaka, M., Duncan, D.R., Conner, T.W. and Wan, Y. (1997). Genetic transformation of wheat mediated by Agrobacterium tumefaciens. Plant Physiol. 115, 971-980.

45 Comai, L., Facciotti, D., Hiatt, W.R., Thompson, G., Rose, R.E. and Stalker, D.M. (1985). Expression in plants of a mutant aroA gene from Salmonella typhimurium confers tolerance to glyphosate. Nature 317, 741-744.

46 Abel, P.P., Nelson, R.S., De, B., Hoffmann, N., Rogers, S.G., Fraley, R.T. and Beachy, R.N. (1986). Delay of disease development in transgenic plants that express the tobacco mosaic virus coat protein gene. Science 232, 738-743.

47 Mariani, C., De Beuckeleer, M., Truettner, J., Leemans, J. and Goldberg, R.B. (1990). Induction of male sterility in plants by a chimaeric ribonuclease gene. Nature 347, 737-741.

48 Van der Krol, A.R., Lenting, P.E., Veenstra, J., Van der Meer, I.M., Koes, R.E., Gerats, A.G.M., Mol, J.N.M. and Stuitje, A.R. (1988). An anti-sense chalcone synthase gene in transgenic plants inhibits flower pigmentation. Nature 333, 866-869.

49 Vaeck, M., Reynaerts, A., Höfte, H., Jansens, S., De Beuckeleer, M., Dean, C., Zabeau, M., Van Montagu, M. and Leemans, J. (1987). Transgenic plants protected from insect attack. Nature 328, 33-37.

50 De Luca, V., Marineau, C. and Brisson, N. (1989). Molecular cloning and analysis of cDNA encoding a plant tryptophan decarboxylase: Comparison with animal dopa decarboxylases. Proc. Natl. Acad. Sci. USA 86, 2582-2586.

51 Pasquali, G., Goddijn, O.J.M., De Waal, A., Verpoorte, R., Schilperoort, R.A., Hoge, J.H.C. and Memelink, J. (1992). Coordinated regulation of two indole alkaloid biosynthetic genes from Catharanthus roseus by auxin and elicitors. Plant Mol. Biol. 18, 1121-1131.

52 Büschges, R., Hollrichter, K., Panstruga, R., Simons, G., Wolter, M., Frijters, A., Van Daelen, R., Van der Lee, T., Diergaarde, P., Groenendijk, J., Töpsch, S., Vos, P., Salamini, F. and Schulze-Lefert, P. (1997). The barley Mlo gene: a novel control element of plant pathogen resistance. Cell 88, 695-705.

53 Guivarc'h, A., Caissard, J.-C., Brown, S., Marie, D., Dewitte, W., Van Onckelen, H. and Chriqui, D. (1993). Localization of target cells and improvement of Agrobacterium-mediated transformation efficiency by direct acetosyringone pretreatment of carrot root discs. Protoplasma 174, 10-18.

54 Villemont, E., Dubois, F., Sangwan, R.S., Vasseur, G., Bourgeois, Y. and Sangwan-Norreel, B.S. (1997). Role of the host cell cycle in the Agrobacterium-mediated genetic transformation of Petunia: evidence of an S-phase control mechanism for T-DNA transfer. Planta 201, 160-172. 
55 Perl, A., Lotan, O., Abu-Abied, M. and Holland, D. (1996). Establishment of an Agrobacteriummediated transformation system for grape (Vitis vinifera L.): The role of antioxidants during grapeAgrobacterium interactions. Nature Biotechnology 14, 624-628.

56 Chilton, M.-D., Tepfer, D.A., Petit, A., David, C., Casse-Delbart, F. and Tempé, J. (1982). Agrobacterium rhizogenes inserts T-DNA into plants roots. Nature 295, 432-434.

57 Tepfer, D. (1984). Transformation of several species of higher plants by Agrobacterium rhizogenes: sexual transmission of the transformed genotype and phenotype. Cell 37, 959-967.

58 Simpson, R.B., Spielmann, A., Margossian, L. and McKnight, T.D. (1986). A disarmed binary vector from Agrobacterium tumefaciens functions in Agrobacterium rhizogenes. Plant Mol. Biol. 6, 403-415.

59 Ooms, G., Hooykaas, P.J.J., Moolenaar, G. and Schilperoort, R.A. (1981). Crown gall plant tumors of abnormal morphology, induced by Agrobacterium tumefaciens carrying mutated octopine Ti plasmids: analysis of T-DNA functions. Gene 14, 33-50.

60 Meyer, P., Linn, F., Heidmann, I., Meyer, H., Niedenhof, I. and Saedler, H. (1992). Endogenous and environmental factors influence $35 \mathrm{~S}$ promoter methylation of a maize $\mathrm{A} 1$ gene construct in transgenic petunia and its colour phenotype. Mol. Gen. Genet. 231, 345-352.

61 Van der Graaff, E. and Hooykaas, P.J.J. (1996). Improvements in the transformation of Arabidopsis thaliana C24 leaf-discs by Agrobacterium tumefaciens. Plant Cell Rep. 15, 572-577.

62 Schmülling, T. and Schell, J. (1993). Transgenic tobacco plants regenerated from leaf disks can be periclinal chimeras. Plant Mol. Biol. 21, 705-708.

63 Ingelbrecht, I., Breyne, P., Vancompernolle, K., Jacobs, A., Van Montagu, M. and DePicker, A. (1991). Transcriptional interference in transgenic plants. Gene 109, 239-242.

64 Pröls, F. and Meyer, P. (1992). The methylation patterns of chromosomal integration regions influence gene activity of transferred DNA in Petunia hybrida. Plant J. 2, 465-475.

65 Breyne, P., Van Montagu, M. and Gheysen, G. (1994). The role of scaffold attachment regions in the structural and functional organization of plant chromatin. Transgenic Res. 3, 195-202.

66 Mlynarova, L., Jansen, R.C., Conner, A.J., Stiekema, W.J. and Nap, J.-P. (1995). The MAR-mediated reduction in position effect can be uncoupled from copy number-dependent expression in transgenic plants. Plant Cell 7, 599-609.

67 Kooter, J.M. and Mol, J.N.M. (1993). Trans-inactivation of gene expression in plants. Curr. Opinion Biotechnol. 4, 166-171.

68 Meyer, P. and Saedler, H. (1996). Homology-dependent gene silencing in plants. Annu. Rev. Plant Physiol. Plant Mol. Biol. 47, 23-48.

69 Haring, M.A., Rommens, C.M.T., Nijkamp, H.J.J. and Hille, J. (1991). The use of transgenic plants to understand transposition mechanisms and to develop transposon tagging strategies. Plant Mol. Biol. 16, 449-461.

70 Aarts, M.G.M., Dirkse, W.G., Stiekema, W.J. and Pereira, A. (1993). Transposon tagging of a male sterility gene in Arabidopsis. Nature 363, 715-717.

71 Koes, R., Souer, E., Van Houwelingen, A., Mur, L., Spelt, C., Quattrocchio, F., Wing, J., Oppedijk, B., Ahmed, S., Maes, T., Gerats, T., Hoogeveen, P., Meesters, M., Kloos, D. and Mol, J.N.M. (1995). Targeted gene inactivation in petunia by PCR-based selection of transposon insertion mutants. Proc. Natl. Acad. Sci. USA 92, 8149-8153.

72 Krysan, P.J., Young, J.C., Tax, F. and Sussman, M.R. (1996). Identification of transferred DNA insertions within Arabidopsis genes involved in signal transduction and ion transport. Proc. Natl. Acad. Sci. USA 93, 8145-8150.

73 McKinney, E.C., Ali, N., Traut, A., Feldmann, K.A., Belostotsky, D.A., McDowell, J.M. and Meagher, 
R.B. (1995). Sequence-based identification of T-DNA insertion mutations in Arabidopsis: actin mutants act2-1 and act4-1. Plant J. 8, 613-622.

74 Morton, R. and Hooykaas, P.J.J. (1995). Gene Replacement. Mol. Breeding 1, 123-132.

75 Reiss, B., Klemm, M., Kosak, H. and Schell, J. (1996). RecA protein stimulates homologous recombination in plants. Proc. Natl. Acad. Sci. USA 93, 3094-3098.

76 Schaefer, D.G. and Zrijd, J.-P. (1997). Efficient gene targeting in the moss Physcomitrella patens. Plant J. 11, 1195-1206.

77 Dale, E.C. and Ow, D.W. (1991). Gene transfer with subsequent removal of the selection gene from the host genome. Proc. Natl. Acad. Sci. USA 88, 10558-10562.

78 Ebinuma, H., Sugita, K., Matsunaga, E. and Yamakado, M. (1997). Selection of marker-free transgenic plants using the isopentenyl transferase gene. Proc. Natl. Acad. Sci. USA 94, 2117-2121. 